\title{
Prevention of Group B Streptococcal Colonization with Topically Applied Lipoteichoic Acid in a Maternal-Newborn Mouse Model
}

\author{
FREDERICK $\operatorname{COX}^{(22)}$ \\ Department of Pediatrics, Medical College of Georgia, Augusta, Georgia, USA
}

\begin{abstract}
Summary
An animal model of maternal-newborn transmission of group B streptococci (GBS) was developed. Pregnant Swiss-Webster mice were colonized by applying $10^{8} \mathrm{GBS}$ to the oral cavity, vagina, and nipples daily for 3 days before delivery. Lipoteichoic acid (LTA) from type III GBS or phosphate buffered saline was applied topically to the oral cavity, perineum or nape of newborn mice.

Cultures of newborn mice at 3 days of age revealed 35 of 75 (47\%) controls and 0 of 79 animals given 2 doses of LTA ( $2 \mathrm{mg} /$ ml) were positive for GBS at one or more sites. One to two\% of control and LTA-treated mice remained culture positive at 7 days of age. None developed GBS disease and no obvious toxicity was noted. This is the first in vivo evidence that colonization with GBS can be prevented by interfering with their adherence to epithelial surfaces.

LTA also prevented colonization by 60,000 GBS in the oral cavity of 1-day-old newborn mice. A minimum concentration of 0.5 mg LTA/ml was required and similar dose response curves were obtained in preventing maternal-newborn transmission or oral newborn colonization. LTA from type III GBS also protected against types Ia and II. Only 6 of $15(40 \%)$ vaginally colonized, nonpregnant mice became noncolonized 3 days after LTA treatment.
\end{abstract}

\section{Speculation}

Topically applied lipoteichoic acid from group B streptococci may be a useful method of preventing GBS colonization and/or disease in human infants at birth if it is nontoxic. The method avoids the problems associated with antibiotic prophylaxis and vaccine development.

Group B streptococci (GBS) are a significant cause of neonatal morbidity and mortality. Early onset disease, characterized by sepsis and meningitis, is the more common type and is acquired from the ano-genital tract of the mother at birth $(3,4)$. Attempts at antibiotic prophylaxis in newborn infants $(14,17)$ and pregnant women (19) have met with varied success and further study is needed. Development of a vaccine for antibody deficient mothers will be difficult and time-consuming (4). Development of alternate methods of prophylaxis are needed.

In 1975, Beachey (6) showed that lipoteichoic acid (LTA) in the cell wall of group A streptococci was responsible for binding of these organisms to oral mucosal cells in vitro. Pretreatment of oral epithelial cells with purified LTA inhibited 78\% of added streptococci from binding. In 1977, Ofek et al. (12) showed that LTA from group A streptococci inhibited group B streptococcal binding to the same degree.

Topical application of LTA to a mucosal surface at birth could potentially prevent or reduce colonization with GBS. This method would avoid the disadvantages of antibiotic prophylaxis and some of the difficulties in vaccine development. Because the method has not been tested in vivo, an animal model of maternal-newborn transmission of GBS was developed.

\section{MATERIALS AND METHODS}

Organisms. Prototype strains type I a (SS-615) and type II (SS619) and wild strain type III (DS-2434-80), beta-hemolytic group B streptococci were supplied by Richard Facklam, Ph.D. at the Centers for Disease Control in Atlanta, Georgia.

Bacterial counts were made using standard surface plating techniques and standardized suspensions measured with a spectrophotometer (12).

Lipoteichoic acid. Purified lipoteichoic acid was prepared from type III GBS by the method of Alkan and Beachey (1). Briefly, this involved growth of GBS in Todd-Hewitt broth (THB) and stimulation with penicillin $G$ during log-phase growth to excrete LTA into the medium. This was followed by phenol precipitation, purification on Sepharose 6B and Biogel P6 columns, dialysis, evaporation and lyophilization. About $80 \mathrm{mg}$ of LTA was obtained from 4 liters of THB culture. The crystalline solid was dissolved in sterile phosphate buffered saline (PBS) $(0.02 \mathrm{M}$ phosphate, $0.15 \mathrm{M} \mathrm{NaCl}, \mathrm{pH} 7.4$ ) before use. No residual penicillin remained in the final preparation (tested by a microbiologic method (15) sensitive to $l \mu \mathrm{g}$ penicillin $/ \mathrm{ml}$ or greater). The final solution was culturally sterile when tested by routine bacteriologic and mycologic methods. Small aliquots of LTA in PBS were stored frozen at $-70^{\circ} \mathrm{C}$ until use.

Adherence testing. Buccal epithelial cells (BEC) were collected from healthy, nonsmoking adults by gentle repeated scraping of the inside of the cheek with a sterile, wooden coffee stirrer. Subjects were fasting for $1 \mathrm{~h}$ before BEC were obtained. Cells were suspended in $2 \mathrm{ml}$ of sterile PBS and washed 3 times with cold $\left(4^{\circ} \mathrm{C}\right)$ PBS to remove nonadherent bacteria and debri.

Adherence testing was performed in the method of Gibbons and van Houte (10). Briefly, suspensions of $10^{5} \mathrm{BEC} / \mathrm{ml}$ and $10^{8}$ $\mathrm{GBS} / \mathrm{ml}(0.6 \mathrm{OD})$ were prepared in PBS. Cells and GBS $(0.5 \mathrm{ml}$ of each) were mixed for $30 \mathrm{~min}$ at room temperature in a rotary, end-over-end mixer. The mixture was washed 3 times with sterile, cold PBS and the final cell button placed on a slide and air dried. After crystal violet staining, the number of streptococci adhering to $50 \mathrm{BEC}$ was determined and results expressed as the mean number of streptococci adherent/BEC.

The inhibitory effect of LTA on adherence was determined by treating washed BEC with various concentrations of LTA before mixing them with streptococci (13). The duration of LTA effectiveness in a moving liquid, like saliva in the mouth, was determined by rotating LTA-treated cells in $2 \mathrm{ml}$ of PBS at $25^{\circ} \mathrm{C}$ for $30 \mathrm{~min}$ and periodically testing an aliquot for GBS adherence.

Cultures. Cultures were obtained on a calcium alginate swab (Inolex Corporation, Glenwood, IL) premoistened in sterile PBS. Swabs were placed into $2 \mathrm{ml}$ of THB containing $5 \%$ defibrinated sheep blood, naladixic acid $(15 \mu \mathrm{g} / \mathrm{ml})$ and gentamicin sulfate $(8$ $\mu \mathrm{g} / \mathrm{ml}$ ) (5) and incubated overnight at $37^{\circ} \mathrm{C}$. Cultures were then streaked on 5\% sheep blood agar (Carr-Scarborough Microbiolog- 
icals, Inc., Stone Mountain, GA) incubated overnight at $37^{\circ} \mathrm{C}$ and observed for typical beta hemolytic colonies. Identification of GBS was confirmed by a positive CAMP test and lack of sensitivity to the bacitracin disc (18). Oral and vaginal or perineal cultures of normal pregnant and nonpregnant Swiss-Webster mice and their offspring revealed no other catalase negative, small, beta hemolytic colonies of bacteria present at any of the sites tested. When swarming Proteus species was present on initial isolation, the original broth was subcultured on colistin-naladixic acid agar (Columbia CNA plates; Carr-Scarborough Microbiologicals, Inc.).

Oral cavity and nape cultures from newborn mice were initially streaked directly on McConkey agar plates for semiquantitation of gram negative bacilli (light growth $=1-5$ colonies, moderate growth $=6-25$ colonies and heavy growth $>25$ colonies/plate). The latter organisms were identified by routine bacteriologic methods.

Animals. Pregnant and nonpregnant female Swiss-Webster mice (Harlan Industries, Inc., Indianapolis, IN) were used in all experiments. Approximation of the delivery date could be estimated within 1-2 days in timed and untimed pregnant animals.

Pregnant mice were colonized with type III GBS daily for 3 days before delivery. The mouth and vaginal canal were innoculated with $5 \times 10^{8}$ and $2.5 \times 10^{8}$ GBS respectively, using a micropipette (8). The nipple line of the mother was swabbed with a sterile cotton tipped applicator moistened in a solution of $10^{10}$ $\mathrm{GBS} / \mathrm{ml}$. Suckling mice were thus exposed to GBS in the vaginal canal at birth, on the nipples when nursing and in the mouth of the mother when licked and picked up (nape of the neck). Vaginal cultures were repeated within $24 \mathrm{~h}$ of delivery. Nonpregnant mice were vaginally colonized for 3 days as described above.

Lipoteichoic acid was then applied topically to newborn mice to prevent colonization in two separate experiments. In each experiment, the mouth, perineum, and nape of the neck of the newborn mice were cultured for GBS at birth and on the 3rd, 5th

Table 1. Duration of the inhibitory effect of lipoteichoic acid on group $B$ streptococcal adherence in vitro ${ }^{1}$

\begin{tabular}{ccc}
$\begin{array}{c}\text { Mixing time } \\
(\mathrm{h})^{2}\end{array}$ & $\begin{array}{c}\text { Mean number of } \\
\text { GBS/cell }\end{array}$ & $\begin{array}{c}\text { \% Reduction in } \\
\text { adherence }\end{array}$ \\
\hline None & 23 & 74 \\
1 & 24 & 73 \\
2 & 37 & 58 \\
3 & 50 & 43 \\
4 & 72 & 18 \\
5 & 85 & 3 \\
6 & 87 & 1 \\
\hline
\end{tabular}

${ }^{1} 10^{5} \mathrm{BEC}$ pretreated with $2 \mathrm{mg} / \mathrm{ml}$ lipoteichoic acid (LTA) solution at $25^{\circ} \mathrm{C}$ for $30 \mathrm{~min}$. Initially, in control cells without LTA, $88 \pm 3.1$ group B streptococci (GBS) adhered/BEC. Untreated control cells washed in sterile phosphate buffered saline revealed $83 \pm 2.2$ adherent GBS/cell at $3 \mathrm{~h}$ and $81 \pm 2.0 \mathrm{GBS} /$ cell at $5 \mathrm{~h}$.

${ }^{2}$ Pretreated cells were rotated end-over-end in sterile phosphate buffered saline at $25^{\circ} \mathrm{C}$ and aliquots tested for GBS adherence at the times given. and 7 th days of life. Lipoteichoic acid $(2 \mathrm{mg} / \mathrm{ml})$ was applied (after cultures were obtained) to the perineum, nape of the neck and oral cavity with a calcium alginate swab or micropipette (2 $\mu l$ in the oral cavity) at various times after birth. Control animals received no treatment (Experiment I) or PBS treatment (Experiment II).

\section{RESULTS}

Adherence. Pretreatment of BEC with LTA at a concentration of $1 \mathrm{mg} / \mathrm{ml}$ reduced adherence $67 \%$ from a mean of $88 \mathrm{GBS} / \mathrm{BEC}$ (untreated) to $29 \mathrm{GBS} / \mathrm{BEC}$. This compared favorably to the $78 \%$ inhibition achieved by Beachey (6) with $1 \mathrm{mg} / \mathrm{ml}$ of LTA from group A streptococci. The duration of the inhibitory effect of LTA on GBS adherence in a moving liquid (PBS) in vitro was approximately $5 \mathrm{~h}$ (Table 1).

Maternal-newborn transmission. Lipoteichoic acid was initially applied at a concentration of $2 \mathrm{mg} / \mathrm{ml}$ (in error) at 2-10 h after birth. Results (Table 2 ) revealed that colonization in newborn control mice was not detectable at birth and persisted for 7 days in only $6 \%$ of animals. By 3 days of age, suckling mice were completely protected from GBS colonization if they received two or more applications of LTA within $6 \mathrm{~h}$ after birth (54\% of control animals colonized versus $0 \%$ with two or more treatments). A small number $(4 \%)$ of all treated newborn mice also remained colonized by 7 days of age.

Because the multiple treatment groups of mice in experiment I included only 37 animals at 3 days of age, the study was repeated (experiment II) comparing controls and group IV $(2+6-\mathrm{h}$ treatment). Results (Table 3 ) were the same as in experiment I. Thus, 35 of $75(47 \%)$ control mice became colonized at 1 or more sites by 3 days of age compared to 0 of 79 mice treated with two or more applications of LTA.

Thirty-seven $(56 \%)$ of 66 colonized newborns were culturepositive at one site, $21(32 \%)$ at two sites and eight (12\%) at three sites. The oral cavity was most frequently colonized in both experiments (68 of 123 or $55 \%$ of culture positive sites) followed by the nape $(24 \%)$ and the perineum $(21 \%)$. Vaginal cultures taken within $24 \mathrm{~h}$ of delivery were positive for GBS in all of the mice in both experiments. No change in the numbers or types of gram negative rods present in the oral cavity or nape were noted in control or treated suckling mice during the 1 wk of observation. Proteus and Pseudomonas species were predominant and Escherichia coli was rarely observed.

Oral colonization. In separate experiments, groups of 10 normal newborn mice (1-2 days old) born to noncolonized mothers, were innoculated orally with $1 \times 10^{4}$ to $6 \times 10^{4} \mathrm{GBS}$. Results revealed that 60,000 GBS was the lowest number of organisms that colonized the oral cavity of $100 \%$ of newborn mice at 3 days of age. One day old suckling mice (groups of 15) were then treated with various concentrations of LTA given as two oral doses $(2 \mu \mathrm{l}$ each) $4 \mathrm{~h}$ apart and then colonized orally with $60,000 \mathrm{GBS} 2 \mathrm{~h}$ after the second dose. Maternal-newborn transmission studies were also repeated with the same LTA concentrations in groups of 15 suckling mice. Results, given in Figure 1, reveal similar inhibitory effects at 3 days of age at each LTA concentration in each system. Newborn mice, in either system, who had received successful

Table 2. Experiment I results of lipoteichoic acid inhibition of maternal-newborn transmission of group B streptococci

\begin{tabular}{|c|c|c|c|c|}
\hline & Birth & 3 Days & 5 Days & 7 Days \\
\hline I (controls) ${ }^{1}$ & $0 / 28^{2}(0 \%)$ & $15 / 28(54 \%)$ & $11 / 27(41 \%)$ & $1 / 18(6 \%)$ \\
\hline II $(2 \text {-h treatment })^{3}$ & $10 / 25(40 \%)$ & $5 / 20(25 \%)$ & $0 / 20(0 \%)$ & $1 / 20(5 \%)$ \\
\hline III (6-h treatment) & $4 / 24(17 \%)$ & $8 / 23(35 \%)$ & $0 / 22(0 \%)$ & $1 / 22(5 \%)$ \\
\hline$V(2+6+10-h$ treatment $)$ & $1 / 19(5 \%)$ & $0 / 19(0 \%)$ & $0 / 17(0 \%)$ & $0 / 17(0 \%)$ \\
\hline$I V+V$ combined & $8 / 37(22 \%)$ & $0 / 37(0 \%)$ & $0 / 34(0 \%)$ & $1 / 33(3 \%)$ \\
\hline
\end{tabular}

' Control animals delivered $24 \mathrm{~h}$ earlier than expected and thus the mothers were colonized for only 2 days before delivery in this experiment.

${ }^{2}$ Number of suckling mice colonized with group B streptococci at any site/number tested (\%). Control animals received no treatment.

${ }^{3}$ Lipoteichoic acid solution $(2 \mathrm{mg} / \mathrm{ml})$ was applied topically to the mouth, nape of neck, and perineum at the times noted after birth. 
Table 3. Experiment I and II results of lipoteichoic acid (LTA) inhibition of maternal-newborn transmission of group B streptococci ${ }^{1}$

\begin{tabular}{|c|c|c|c|c|}
\hline & Birth & 3 Days & 5 Days & 7 Days \\
\hline \multicolumn{5}{|c|}{ Controls (seven litters) } \\
\hline Experiment I & $0 / 28(0 \%)$ & $15 / 28(54 \%)$ & $11 / 27(41 \%)$ & $1 / 18(6 \%)$ \\
\hline Experiment $\mathrm{II}^{2}$ & $0 / 48(0 \%)$ & $20 / 47(43 \%)$ & $0 / 47(0 \%)$ & $0 / 44(0 \%)$ \\
\hline \multicolumn{5}{|c|}{ LTA Treated (eight litters) } \\
\hline Experiment $\mathbf{I}^{3}$ & $8 / 37(22 \%)$ & $0 / 37(0 \%)$ & $1 / 34(3 \%)$ & $1 / 33(3 \%)$ \\
\hline
\end{tabular}

\footnotetext{
${ }^{1}$ Results expressed are the number of suckling mice colonized with group B streptococci at any site/number tested (\%).

${ }^{2}$ Control animals were treated with sterile phosphate buffered saline.

${ }^{3}$ Treated 2 and 6 or 2,6 , and $10 \mathrm{~h}$ after birth.

${ }^{4}$ Treated 2 and $6 \mathrm{~h}$ after birth.
}

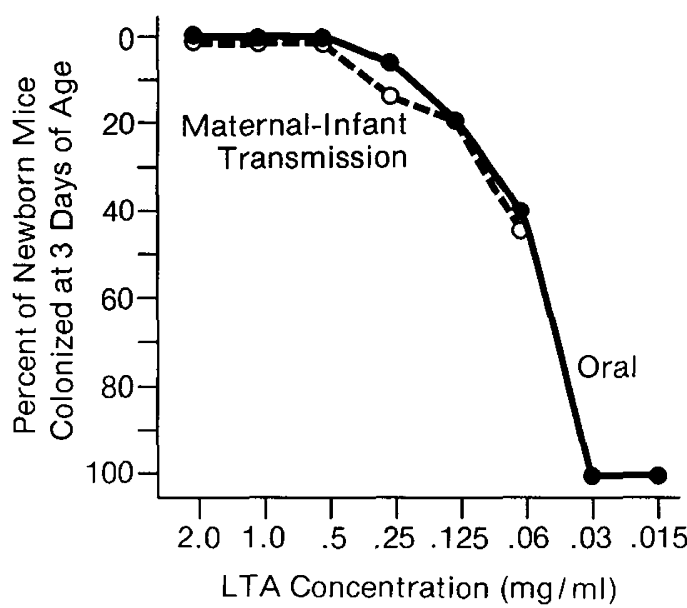

Fig. 1. Dose-response curve for lipoteichoic acid (LTA) in 1-day-old newborn mice. Prevention of oral colonization and maternal-fetal transmission of group B streptococci (GBS) at 3 days of age. Each point represents results in 15 or more mice (see text).

prophylaxis at birth, could be recolonized at 3 days of age. Oneday-old newborn mice colonized orally with 60,000 GBS and culture positive at 3 days of age, became culture negative by 7 days of age. Attempts at prevention of oral colonization with one oral dose of LTA resulted in only partial protection with three of $15(20 \%)$ mice colonized at 3 days of age after the $2 \mathrm{mg} / \mathrm{ml}$ dose and 10 of $15(66 \%)$ after the $0.5 \mathrm{mg} / \mathrm{ml}$ dose. Repetition of the oral colonization experiments using 2 doses of the type III LTA and type Ia or II GBS revealed complete cross-protection (100\% of 30 animals) for the other serotypes. Varying the time between the two LTA doses from $30 \mathrm{~min}$ to $3 \mathrm{~h}$ also provided complete protection with the $0.5 \mathrm{mg} / \mathrm{ml}$ concentration.

Toxicity. No obvious toxicity was observed. Unexplained deaths of newborn mice occurred in experiments I and II in five (7\%) of controls and $11(14 \%)$ of 79 LTA-treated animals (three of the 11 were runts); however, in experiment II, unexplained newborn deaths occurred in four of 47 controls and in zero of 42 LTAtreated mice. Eighteen $\%$ of newborn mice were cannibalized in experiment I and 4\% in experiment II. No unexplained deaths occurred in the other maternal-newborn transmission or any of the oral treatment studies. At autopsy, no evidence of infection (by culture of the lungs and liver) or gross abnormalities were noted in the dead mice.

Nonpregnant mice. Groups of five nonpregnant mice were vaginally colonized with $10^{4}-10^{7}$ GBS daily for 3 days. The lowest dose that colonized all five animals by day 3 after innoculation was $10^{5}$ GBS. Repeat vaginal cultures on days 7 and 14 were negative for GBS.

Prophylaxis was also attempted in nonpregnant mice vaginally colonized for 3 days with $10^{5}$ GBS. Treatment solutions were applied on the 4th day in two doses $4 \mathrm{~h}$ apart. Results revealed that LTA $(0.5 \mathrm{mg} / \mathrm{ml})$ was effective in six of $15(40 \%)$ animals by day 3. Streptococci were again cleared in $1 \mathrm{wk}$ in both LTAtreated and control groups.

\section{DISCUSSION}

This is the first in vivo data demonstrating that colonization with GBS can be prevented by interfering with adherence. Topical application of the streptococcal ligand, LTA, presumably fills the vacant GBS receptor sites on surface epithelial cells and provides protection for 5-6 h. When the few GBS adherent to a newborn mouse born to a colonized mother begin to multiply, they cannot attach and are probably shed into the external environment or the moisture on a mucosal surface. Other nonspecific cleansing mechanisms such as the flow of saliva, desquamation of epithelial cells and muscular movements of the mouth would assist in removing GBS remaining in the oral cavity (9).

Lipoteichoic acid would theoretically be most effective if applied before the organisms could double in number. The in vitro doubling time of GBS is about $30 \mathrm{~min}$ (16). Although the in vivo doubling time of oral bacteria is unknown (11), it is estimated to be 6-8 h for streptococci (Personal communication, George Schuster, Ph.D., M.C.G.). Because the LTA is applied within $6 \mathrm{~h}$ of colonization, this is another probable reason for its effectiveness.

This method of GBS prophylaxis, if found to be safe and nontoxic, may be useful in preventing GBS colonization in human infants during the first wk of life.

The animal model developed in this study provided consistently reproducible results with maternal-newborn transmission and newborn oral colonization without the development of disease. A similar model in rats also revealed that $51 \%$ of rat pups born to vaginally colonized mothers were colonized in the throat or perianal area (2). A previous study in Cornett strain mice (8) was unable to detect newborn transmission due to overgrowth of gramnegative organisms obscuring the GBS. The use of a selective broth medium with antibiotics in the present study and the rat study (2) permitted easy identification of GBS. Host defenses in the suckling mice rapidly cleared $6 \times 10^{4}$ streptococci from oral epithelial surfaces by 7 days of age in the present study; however, colonization persists for 14 days without disease if $1 \times 10^{8}$ organisms are used as the oral innoculum (8). This data confirms that newborn mice are also an ideal model for the study of GBS colonization without disease.

Multiple doses of LTA were probably needed for protection in mice in order to fill all the binding sites on a mucosal surface with a moving liquid. This is confirmed by the lack of variation in effectiveness when the time between LTA doses was varied.

Newborn mice born to colonized mothers were most frequently culture positive in the oral cavity. This was most likely acquired from the vaginal canal or nipples of the mother. Mice were frequently colonized at multiple sites but most commonly in the 
oral cavity compared to human infants who are more commonly culture positive in the rectum and umbilical cord $(3,7)$.

The similar LTA inhibition curves (Fig. 1) suggest that newborn mice are colonized with $6 \times 10^{4} \mathrm{GBS}$ or less from the mother. Very small amounts of LTA were protective $(0.2 \mu \mathrm{g}$ in the oral cavity) in either system.

Unexplained newborn deaths were most likely due to frequent handling of the animals because the deaths and cannibalization were noted in initial experiments and not thereafter. The absence of systemic infection in newborn rats and mice colonized with GBS has been noted previously $(2,8)$ and suggests that a high degree of local and/or systemic immunity of GBS exists at birth in these animals.

Lipoteichoic acid was only partially effective in reducing colonization in previously colonized, nonpregnant mice suggesting a lack of utility in maternal prophylaxis against newborn transmission.

\section{REFERENCES AND NOTES}

1. Alkan, M. L. and Beachey, E. H.: Excretion of lipoteichoic acid by group A streptococci. Influence of penicillin on excretion and loss of ability to adhere to human oral mucosal cells. J. Clin. Invest., 61: 67I (1978).

2. Ancona, R. J. and Ferrieri, P.: Experimental vaginal colonization and motherinfant transmission of group B streptococci in rats. Infect. Immun., 26: 599 (1979).

3. Anthony, B. F. and Okada, D. M.: The emergence of group B streptococcal infections of the newborn infant. Ann. Rev. Med., 28: 355 (1977).

4. Baker, C. J.: Group B streptococcal infections in neonates. Pediatrics in Review, 1: 5 (1979).

5. Baker, C. J., Clark, D. J., and Barrett, F. F.: Selective broth medium for isolation of group B streptococci. Appl. Microbiol., 26: 884 (1973).

6. Beachey, E. H.: Binding of group A streptococci to human oral mucosal cells by lipoteichoic acid. Trans. Assoc. Am. Phys., 88: 285 (1975).

7. Ferrieri, P., Cleary, P. P., and Seeds, A. E.: Epidemiology of group B streptococcal carriage in pregnant women and newborn infants. J. Med. Microbiol., 10: 103 (1977).

8. Furtado, D.: Experimental group B streptococcal infections in mice: Hematogenous virulence and mucosal colonization. Infect. Immun., 13: 1315 (1976).

9. Gibbons, R. J.: Adherence of Bacteria to Host Tissue, in Schlessinger, D. (ed.): Microbiology (Washington, D.C.: American Society for Microbiology, 1977).

10. Gibbons, R. J. and van Houte, J.: Selective bacterial adherence to oral epithelial surfaces and its role as an ecological determinant. Infect. Immun., 3: 567 (1971).

11. Nolte, W. A. (Ed.): Oral Microbiology with Basic Microbiology and Immunology, Third Edition, p. 205, (C. V. Mosby Company, St. Louis, 1977).

12. Ofek, I., Beachey, E. H., Eyal, F., and Morrison, J. C.: Postnatal development of binding of streptococci by oral mucosal cells of humans. J. Infect. Dis., 135: 267 (1977).

13. Ofek, I., Beachey, E. H., Jefferson, W., and Campbell, G. L.: Cell membranebinding properties of group A streptococcal lipoteichoic acid. J. Exp. Med., 141: 990 (1975).

14. Paredes, A., Wong, P., and Yow, M. D.: Failure of penicillin to eradicate the carrier state of group B streptococcus in infants. J. Pediatr., 89: 191 (1976).

15. Sabbath, L.: Rapid assay of some nephrotoxic antibiotics and the assay of antibiotics in mixtures. In Analytical Microbiology, Frederick Kavanagh, Editor, Volume 2, Chapter 4, Part II, (Academic Press, Inc., New York, 1972).

16. Schauf, V., Deveikis, A., Riff, L., and Serota, A.: Antibiotic-killing kinetics of group B streptococci. J. Pediatr., 89: 194 (1976).

17. Siegel, J., McCracken, G. H. Jr., Threlkeld, N., Milvenan, B., and Rosenfeld, C. R.: Single-dose penicillin prophylaxis against neonatal group B streptococcal infections. A controlled trial in 18,738 newborn infants. N. Engl. J. Med., 303: 769 (1980).

18. Waitkins, S. A.: Evaluation of rapid methods of identifying group B streptococci. J. Clin. Pathol., 33: 302 (1980).

19. Yow, M. D., Mason, E. O., Leeds, L. J., Thompson, P. K., Clark, O. J., and Gardner, S. E.: Ampicillin prevents intrapartum transmission of group B streptococcus. J. Am. Med. Assoc., 24I: 1245 (1979).

21. The author is grateful to Luann Taylor for technical assistance and Pat Miller for typing of the manuscript.

22. Requests for reprints should be addressed to: Dr. Frederick Cox, Department of Pedriatrics, Medical College of Georgia, Augusta, GA, 30912.

23. Received for publication October 20,1981

24. Accepted for publication March 4, 1982. 